\title{
Medication Cost of Persons with Dementia in Primary Care in Germany
}

\author{
Bernhard Michalowsky, ${ }^{\mathrm{a}, *}$, Tilly Eichler ${ }^{\mathrm{a}}$, Jochen René Thyrian ${ }^{\mathrm{a}}$, Johannes Hertel ${ }^{\mathrm{a}}$, Diana Wucherer ${ }^{\mathrm{a}}$, \\ Sebastian Laufs ${ }^{\mathrm{c}}$, Steffen Fleßa ${ }^{\mathrm{c}}$ and Wolfgang Hoffmann ${ }^{\mathrm{a}, \mathrm{b}}$ \\ ${ }^{a}$ German Center for Neurodegenerative Diseases (DZNE), Rostock/Greifswald, Greifswald, Germany \\ ${ }^{\mathrm{b}}$ Institute for Community Medicine, Section Epidemiology of Health Care and Community Health, \\ Ernst-Moritz-Arndt-University Greifswald, Greifswald, Germany \\ ${ }^{\mathrm{c}}$ Department of General Business Administration and Health Care Management, Ernst-Moritz-Arndt-University \\ Greifswald, Greifswald, Germany
}

Accepted 16 April 2014

\begin{abstract}
.
Background: Results of cost-of-illness studies in dementia have shown a considerable divergence in costs of medication for persons with dementia. However, detailed economic analyses of medication costs for community-dwelling persons with dementia are currently still missing, especially on the basis of primary data.

Objective: To determine medication cost, cost per drug, and number of drugs taken of community-dwelling persons with dementia and analyze their associated factors; to estimate the current price reduction of anti-dementia drugs due to implementation of low-priced generics.

Method: The present analysis included 205 patients screened positive for dementia. Medication data were assessed within a medication review. To estimate the cost effect of implementing generics, the most favorable equivalent generic was assigned to each anti-dementia drug. Factors associated with medication cost, cost per drug, and number of drugs taken were evaluated using multiple regression models.

Results: Medication cost and cost per drug were higher and the number of taken drugs lower in advanced stages of cognitive impairment. Prescription of anti-dementia generics could decrease overall medication cost by $28 \%$. Medication cost was associated with number of diagnoses, deficits in activities of daily living, and age. Dementia severity was related to cost per drug and number of drugs taken.

Conclusion: Medication cost increases with the number of diagnoses and growing deficits in activities of daily living and decreases with age. Severely cognitively impaired persons are treated with a small number of high-priced drugs, which could suggest inadequate medication of multimorbid persons.
\end{abstract}

Keywords: Dementia, drug substitution, drug therapy, economics, pharmaceutical economics

ClinicalTrials.gov Identifier: NCT01401582

\section{INTRODUCTION}

In industrialized nations, demographic changes are leading to a rapid increase in the number and proportion of the elderly [1]. This goes along with an increase of prevalence and incidence of age-associated illnesses,

\footnotetext{
*Correspondence to: Bernhard Michalowsky, German Center for Neurodegenerative Diseases (DZNE), Rostock/Greifswald, Ellernholzstrasse 1-2, Greifswald D-17487, Germany. Tel.: +49 383486 7591; Fax: +49 383486 19551; E-mail: bernhard. michalowsky@dzne.de.
}

such as dementia, which has become a major challenge for the health care system [1-4]. Dementia is associated with substantial health care costs. In 2008, Germany spent $€ 10.457$ billion (US $\$ 14.215$ billion $^{1}$ ) solely for dementia in the population aged 65 and older, including medical and formal nursing care cost from a payer perspective [5]. Focusing on this population, dementia caused $8.4 \%$ of the overall health care costs [2]. Therefore, dementia is one of the most expensive diseases in old age, and the ongoing demographic change

\footnotetext{
${ }^{1}$ Exchange rate $1 €=1.3594 \$$ (status: Jan 2014)
} 
will thereby have a major impact of expenditures for dementia in the future [5-8].

Evidence-based guidelines [9] for treatment of dementia cover a wide variety of treatment options, such as medical, pharmacological, and psychosocial therapy as well as nursing care and others. The prescription of anti-dementia drugs (e.g., acetylcholinesterase inhibitors such as donepezil, galantamine, and rivastigmine or the $\mathrm{N}$-methyl-D-aspartate antagonist memantine) is currently considered the primary medical treatment for dementia [9]. Adequate pharmacotherapy could slow cognitive decline and preserve cognitive abilities [10], reduce the need for nursing care $[11,12]$, and delay institutionalization [13], all of which are associated with savings in health care costs [11, 13-17].

Economic analyses of health care costs in dementia have been the focus of various cost-of-illness (COI) studies [14, 18-26]. However, so far, little is known on the economics of medication cost themselves [11, 13, 15-17]. Drug treatment of persons with dementia (PWD) is twice as expensive as drug treatment of nondemented patients [27]. Major cost drivers are both psychotropic and anti-dementia drugs [14]. However, these analyses are likely outdated because the patents of cost-intensive original anti-dementia drugs expired in 2010. Subsequently, supplementary protection certificates prevented implementation of lower-priced generic anti-dementia drugs until 2012. Since then, prescription of generics was possible, and manufacturers estimated potential cost reductions of $30 \%$ [28].

In spite of the cost-intensive treatment with antidementia drugs, overall medication of PWD represents only a small proportion of total health care costs in dementia [14, 18-20, 22-24]. Nevertheless, findings of COI studies suggest that medication cost may decrease or at least remain stable during the progression of dementia disease $[19,20,29,30]$. Lopez-Bastida et al. showed a decrease of the proportion of drug cost by $31 \%$ from moderate to severe dementia [29]. The continuously increasing approval of cost-intensive anti-dementia drugs (acetyl-cholinesterase inhibitors in mild to moderate dementia and memantine in moderate to severe dementia) contrasts with findings of these studies [9]. Decreased medication cost could be caused by a decrease in the number of drugs taken, which was also demonstrated by Leicht et al. [20]. This could indicate a less adequate drug treatment of multimorbid PWD. On the other hand cost-intensive anti-dementia drugs may be prescribed less frequently in advanced stages of dementia disease. However, other studies found no significant effects of severity of dementia on health care costs, but instead that deficits in activities of daily living (ADL) and comorbid diseases were associated with higher costs in dementia [31-34].

COI studies focusing on medical and formal nursing care costs in dementia are mostly based on secondary data from a payer perspective and do not always capture the real situation of medication. These analyses include only medication on prescription (Rx-drugs) but do not consider additional over-the-counter pharmaceuticals (OTC-drugs) and are based on daily defined dosage and not on the real individual intake of drugs. Hence, an economic analysis of medication cost and an estimation of potential savings due to the current implementation of generic anti-dementia drugs on the basis of primary data are currently missing.

\section{Aims of the study}

The objectives of this study are (a) to determine total medication cost, cost per drug, and number of drugs taken by patients screened positive for dementia in primary care in relation to the severity of cognitive impairment; (b) to examine the cost of anti-dementia drugs and to estimate medication cost, under the assumption that the analyzed persons currently receive available generic anti-dementia drugs, by using a model calculation; and (c) to identify socio-demographic and clinical factors associated with medication cost, cost per drug, and number of drugs taken.

\section{MATERIAL AND METHODS}

\section{Study design and sample}

The present study is a cross-sectional analysis of medication cost of community-dwelling PWD in primary care. Analyses are based on primary data from the ongoing DelpHi-MV trial (Dementia: Lifeand person-centered help in Mecklenburg-Western Pomerania, Germany), a population-based, clusterrandomized, controlled intervention trial in the primary care setting. Eligible patients (older than 70 years, living at home) were screened in participating general practitioner (GP) practices for dementia using the DemTect [35], which is one of the dementia screening tests most widely used in general practices in Germany [36]. Each patient's caregiver was asked to participate as well. Eligible participants and their caregivers were assigned to an intervention and a control group, respectively, based on their treating GP-practice's randomization into either the control or the intervention group. A comprehensive baseline 
assessment and an annual follow-up were conducted identically in both groups. Whereas participants of the control group received "care as usual", the intervention group received the "DelpHi-Intervention", which was designed to provide "optimum care" to PWD by integrating multi-professional and multimodal strategies to individualize and optimize the treatment of PWD [37]. Baseline assessment, intervention, and annual followups were carried out by specific qualified dementia care managers [36-38].

The baseline assessment included a comprehensive standardized home medication review to assess in detail the actual medication situation of the PWD. The review combined a scan of all medication packages, visitation of places where medication is routinely stored in the PWD's home, a computer-assisted standardized interview, and linkage of the assessed medication with a database covering all available drugs in Germany [37, 39]. The informal caregiver (if present) assisted the PWD in the interview and was asked to validate and complete the information provided. In case of missing data, any available proxies, such as home nursing services, were contacted. The medication review records detailed information about all drugs taken by the PWD, including Rx- and OTC-drugs. In addition, the review included more differentiated data on drugs, in particular the brand name, pharmaceutical registration number, active substance, prescribed package size $(\mathrm{N} 1, \mathrm{~N} 2, \mathrm{~N} 3)$, individual taken dosage, day and time of drug intake, and intake option (e.g., regular intake, emergency drug, in case of urgent need, no longer needed) [39]. This pharmaceutical information was entered into electronic case reporting forms and stored in a study database [40].

Overall, $n=2,893$ people were screened by 60 GPs, and $n=484(17 \%)$ PWD were eligible for the study. A total of $n=290(60 \%)$ agreed to participate, and $n=268$ participants had finished the baseline assessment by September 1, 2013. Sixty-three PWD were excluded from the analyses because of missing data of relevant variables. The primary causes for missing data included dropout due to death $(n=18)$, withdrawal of informed consent $(n=27)$, relocation $(n=3)$, and other reasons $(n=4)$. In $n=10$ patients, the psychometric instruments could not be executed because of the patient's severe dementia. Furthermore, in one patient, medication review was missing. Hence, for the present analyses, data of $n=205$ PWD were available. These participants provided data on a total 1,583 drugs, including Rx- and OTC-drugs. For our analyses, 360 drugs were excluded due to the impossibility of cost calculation (168 only as required drugs, one drug in case of an emergency, 98 stopped or further unknown medication, 34 liquid drugs, 49 insulins, and 10 topical medication), leaving 1,223 drugs for analysis: 1,064 (87\%) Rx-drugs and 153 (13\%) OTC-drugs.

\section{Cost calculations}

Pharmacy sales prices were provided by the Pharmaceutical Index of the Scientific Institute of the AOK (Arzneimittelindex des Wissenschaftlichen Institutes der Ortskrankenkassen - WIdO), which is updated and published monthly [41]. By using the pharmaceutical registration number (PZN) [42], the documented drugs can be directly assigned to the pharmacy sales prices. To evaluate medication cost, a daily dose for each drug taken by PWD was calculated. To account for drugs taken less than daily (factor $=1$ ), the following factors were used to assess the daily intake: every other day $($ factor $=0.5)$, two times a week $($ factor $=2 / 7)$, once a week $($ factor $=1 / 7)$, every two weeks $($ factor $=1 / 14$ ), once every month (factor $=1 / 30$ ), or individual (factor $=1 / 7^{*}$ number of intakes per week). Therefore, a conversion of price per package to price per tablet was conducted. By multiplying price per tablet and daily intake per drug, daily cost per drug was calculated. To calculate medication cost per month, the daily cost was multiplied by 30 days. Additionally, cost per drug was calculated as an average price of all drugs taken by one PWD by dividing monthly medication cost by number of drugs taken. To estimate the cost effect of implementing generic drugs, we assigned the most favorable equivalent generic anti-dementia drug to each original anti-dementia drug (active substances memantine, galantamine, rivastigmine, and donepezil). The allocation was based on the strength of each medication and its prescribed package size.

\section{Socio-demographic and clinical variables}

To analyze the associations of monthly medication cost, average cost per drug and number of drugs taken with clinical and socio-demographic factors from the baseline assessment, age, gender, living situation, cognitive impairment, activities of daily living, comorbidity (number of medical diagnoses), depression, and number of in-hospital stays during the last year were included. Severity of cognitive impairment was assessed by the Mini-Mental Status Test (MMST) [43], a psychometric testing procedure to categorize participants into one of four groups of cognitive impairment: without ( $\geq 27)$, mild (20-26), moderate 
(10-19), and severe $(\leq 9)$. The Bayer Activities of Daily Living Scale (B-ADL) [44] was used to assess deficits in activities of daily living (ADL). Medical diagnoses were obtained from medical records of the treating GP as ICD-10 codes (International Statistical Classification of Diseases and Related Health Problems). In this study, data were combined into simple count scores of diagnoses. Numbers of diagnoses were counted by using the three-digit general scheme (e.g., F01, F02, F03, etc.). Further, the Geriatric Depression Scale (GDS), summarized as a total score [45], and the number of in-hospital stays during the last year (dichotomus: yes/ no) were used in the models.

\section{Statistical analysis}

We used descriptive statistics to analyze total medication cost, cost per drug, and number of drugs taken in PWD with mild, moderate, and severe cognitive impairment. Differences in costs and number of drugs taken between groups of severity were examined using the nonparametric Kruskal-Wallis test. To measure associations of ADL, comorbidity and cognitive impairment with monthly medication cost, a multiple linear regression model was fitted. Gender, age, living situation (dichotomous: alone versus not alone), in-hospital stay during the last year (dichotomous: yes/ no) and depression measured by GDS were included as covariates. To account for dependency of data from multiple PWD of the same GP, we included random effects for each GP. Because of a highly skewed distribution of monthly medication cost, standard errors and confidence intervals for regression coefficients were estimated by bootstrapping $(2,000$ replications) [46]. The same statistical model was fitted with cost per drug as outcome. Number of drugs taken was treated as a Poisson-distributed count variable. We fitted a Poisson regression model with random effects for each GP to analyze the associations of ADL, comorbidity, in-hospital stay and cognitive impairment with the number of drugs taken. To control for sociodemographic characteristics, the same covariates (age, gender, living situation) were included. For standard error estimation, the observed information matrix was used, which is one of the standard procedures. Statistical analyses were performed using the software STATA/IC version 11.0 [47].

\section{RESULTS}

\section{Socio-demographic and clinical characteristics}

A sample of $n=205$ PWD was analyzed. Table 1 presents the sample characteristics. Overall, $64 \%$ $(n=132)$ of the study participants were female. At baseline, PWD were on average 79.6 (SD 5.35) years old. More than half of the sample $(n=106 ; 51.7 \%)$ lived alone in their own household. The mean MMST score was approximately 21.9 (SD 5.38), and males and females had similar mean scores and score distributions. The majority of analyzed PWD $(n=104 ; 50.7 \%)$ were mildly cognitively impaired, compared to $n=49$ (23.9\%) moderately and $n=7(3.4 \%)$ severely cognitive impaired. The remaining $n=45(22.0 \%)$ were not cognitively impaired according to the MMST. A detailed description of participants' socio-demographic and clinical variables referring to different stages of cognitive impairment is represented in the Supplementary Table 1. The mean B-ADL score was 3.56 (SD 2.38), with a range of 1 (not at all impaired) and 9.92 (severely impaired). The mean GDS value was 3.46 (SD 2.63), which was below the limit of depression (score $\geq 6$ ). On average, PWD had 9.24 (SD 4.76) diagnoses according to ICD-10. Overall, $n=48(23.4 \%)$ reported an in-hospital stay during the last year. In total, $n=59$ (28.8\%) PWD received anti-dementia drugs. These participants were younger (mean age: 78.45 versus 80.03 ), significantly more impaired (mean MMST-value: 19.74 versus $22.75 ; p$ value $<0.001$ ) and thus, significantly ( $p$ value $<0.001$ ) more represented in higher stages of cognitive impairment compared to PWD without an anti-dementia drug treatment.

\section{Medication cost, cost per drug, and number of drugs taken}

The unadjusted average medication cost, cost per drug and number of drugs taken by communitydwelling PWD in primary care are presented in Table 2. Overall, average medication cost amounted to $€ 112.37$ (SD 92.31) per month. Nearly half of the sample $(n=102 ; 49.8 \%)$ received drug treatment resulting in cost of more than $€ 100$ per month. Only $n=2(1 \%)$ PWD received no drugs. On average, the number of drugs taken was 5.97 (SD 3.15). This resulted in average cost per drug of approximately $€ 20.40$ (SD 19.21) for the total sample.

Looking at the different stages of cognitive impairment, medication cost was $€ 108.19$ (SD 87.28) in PWD with mild, $€ 118.09$ (SD 105.1) in PWD with moderate and $€ 136.93$ (SD 109.5) in PWD with severe cognitive impairment. Accordingly, medication cost in severely cognitively impaired PWD was about onethird higher than in mildly cognitively impaired PWD. Significant group differences were found for cost per $\operatorname{drug}(p=0.005)$ and number of drugs taken $(p=0.001)$. 
Table 1

Socio-demographic and clinical characteristics of the total study sample and of participants with $(n=59)$ and without $(n=146)$ anti-dementia drug treatment

\begin{tabular}{|c|c|c|c|c|}
\hline & Total sample $n=205$ & PWD with ADD $n=59$ & PWD without ADD $n=146$ & $p$ value \\
\hline \multicolumn{5}{|l|}{ Age } \\
\hline Mean (SD) & $79.58(5.35)$ & $78.45(5.03)$ & $80.03(5.42)$ & \multirow[t]{2}{*}{$0.057^{\mathrm{a}}$} \\
\hline Range & $70-96$ & $70-93$ & $70-96$ & \\
\hline \multicolumn{5}{|l|}{ Gender n (\%) } \\
\hline Female & $132(64.39)$ & $36(61.02)$ & $96(65.75)$ & \multirow[t]{2}{*}{$0.518^{\mathrm{b}}$} \\
\hline Male & $73(35.61)$ & $23(38.98)$ & $50(34.25)$ & \\
\hline \multicolumn{5}{|l|}{$M M S T^{1}$} \\
\hline Mean (SD) & $21.90(5.38)$ & $19.74(5.63)$ & $22.75(5.05)$ & \multirow[t]{2}{*}{$0.001^{\mathrm{a}}$} \\
\hline Range & $5-30$ & $5-29$ & $7-30$ & \\
\hline \multicolumn{5}{|c|}{ Severity of cognitive impairment $n(\%)$} \\
\hline No hint for & $45(21.95)$ & $7(11.86)$ & $38(26.03)$ & \multirow[t]{4}{*}{$0.001^{b}$} \\
\hline Mild & $104(50.73)$ & $25(42.37)$ & $79(54.11)$ & \\
\hline Moderate & $49(23.90)$ & $23(38.98)$ & $26(17.81)$ & \\
\hline Severe & $7(3.42)$ & $4(6.78)$ & $3(2.05)$ & \\
\hline \multicolumn{5}{|l|}{ Living situation $n(\%)$} \\
\hline Alone & $106(51.71)$ & $32(54.24)$ & $74(50.69)$ & \multirow[t]{2}{*}{$0.540^{\mathrm{b}}$} \\
\hline Not alone & $99(48.29)$ & $27(45.76)$ & $72(49.31)$ & \\
\hline \multicolumn{5}{|l|}{ Diagnoses } \\
\hline Mean (SD) & $9.24(4.76)$ & $8.97(5.25)$ & $9.35(4.56)$ & \multirow[t]{2}{*}{$0.606^{\mathrm{a}}$} \\
\hline Range & $0-24$ & $1-24$ & $0-22$ & \\
\hline \multicolumn{5}{|l|}{$B-A D L$} \\
\hline Mean (SD) & $3.56(2.38)$ & $3.97(2.38)$ & $3.40(2.36)$ & \multirow[t]{2}{*}{$0.117^{\mathrm{a}}$} \\
\hline Range & $1-9.92$ & $1-9.92$ & $1-9.70$ & \\
\hline \multicolumn{5}{|l|}{$G D S$} \\
\hline Mean (SD) & $3.45(2.62)$ & $3.41(2.40)$ & $6.62(2.86)$ & \multirow[t]{2}{*}{$0.623^{\mathrm{a}}$} \\
\hline Range & $0-13$ & 0-9 & $0-13.93$ & \\
\hline In-hospital stay $n(\%)$ & $48(23.41)$ & $12(20.34)$ & $36(24.66)$ & $0.254^{\mathrm{b}}$ \\
\hline
\end{tabular}

MMST, Mini-Mental Status Test; B-ADL, Bayer-Activities of Daily Living Scale; GDS, Geriatric Depression Scale; PWD, Persons with Dementia; ADD, Anti-dementia drug treatment. ${ }^{1}$ MMST score reverse-coded; ${ }^{a}$ Differences in means: $t$-test; ${ }^{\mathrm{b}}$ Differences in proportions: Fischer's exact test.

Table 2

Average medication cost, cost per drug, and number of drugs taken for total study sample and people with no $(n=45)$, mild $(n=104)$, moderate $(n=49)$, and severe $(n=7)$ cognitive impairment

\begin{tabular}{|c|c|c|c|c|c|c|c|c|c|c|c|}
\hline & \multicolumn{10}{|c|}{ Cognitive impairment } & \multirow[b]{3}{*}{$p$ value $^{2}$} \\
\hline & \multicolumn{2}{|c|}{$\begin{array}{c}\text { Total sample } \\
n=205\end{array}$} & \multicolumn{2}{|c|}{$\begin{array}{c}\text { No hint of cognitive } \\
\text { impairment } \\
n=45\end{array}$} & \multicolumn{2}{|c|}{$\begin{array}{l}\text { Mild cognitive } \\
\text { impairment } \\
n=104\end{array}$} & \multicolumn{2}{|c|}{$\begin{array}{c}\text { Moderate cognitive } \\
\text { impairment } \\
n=49\end{array}$} & \multicolumn{2}{|c|}{$\begin{array}{c}\text { Severe cognitive } \\
\text { impairment } \\
n=7\end{array}$} & \\
\hline & Mean & $(S D)$ & Mean & $(S D)$ & Mean & $(S D)$ & Mean & $(S D)$ & Mean & $(S D)$ & \\
\hline Medication $\operatorname{cost}^{1}$ in $€$ & 112.37 & $(92.31)$ & 112.02 & $(88.42)$ & 108.19 & $(87.28)$ & 118.09 & $(105.1)$ & 136.93 & (109.5) & 0.916 \\
\hline Cost per drug in $€$ & 20.40 & $(19.21)$ & 16.04 & (12.01) & 18.42 & (15.47) & 22.95 & (17.40) & 60.04 & (54.18) & 0.005 \\
\hline Number of drugs taken & 5.97 & $(3.15)$ & 6.76 & $(2.85)$ & 6.28 & $(3.43)$ & 5.04 & $(2.37)$ & 2.71 & (1.89) & 0.001 \\
\hline
\end{tabular}

SD, standard deviation. ${ }^{1}$ Medication cost per month; ${ }^{2}$ Differences in means: Kruskal-Wallis test.

Mean cost per drug was $€ 18.42$ (SD 15.47) in mildly and $€ 22.95$ (SD 17.40) in moderately cognitively impaired PWD. People with severe cognitive impairment paid $€ 60.04$ (SD 54.18) per drug, more than three times as expensive as for people with mild cognitive impairment. The average number of drugs taken was 6.28 (SD 3.43) in PWD with mild, 5.04 (SD 2.37) in PWD with moderate and only 2.71 (SD 1.89) in PWD with severe cognitive impairment. The medication cost of participants $(n=45)$ without cognitive impairment (MMST $\geq 27$ ) was $€ 112.02$ (SD 88.42). These partic- ipants received on average 6.76 (SD 2.85) drugs. Cost per drug in this group was $€ 16.04$ (SD 12.01).

\section{Cost of anti-dementia drugs and impact of price change due to introduction of generics}

In this analysis, 77 (77\%) drugs for the nervous system (ATC code "N") ranked among the hundred most cost-intensive drugs, and half of these were anti-dementia drugs (ATC code N06D). As described before, a total of $n=59(28.8 \%)$ PWD received 
anti-dementia drugs (acetyl-cholinesterase inhibitors or N-methyl-D-Aspartate antagonists). Another $n=7$ (3.4\%) who received herbal anti-dementia drugs such as Ginkgo biloba were not categorized into this group. Forty-four (74.6\%) of these PWD received original and $n=15(25.4 \%)$ generic anti-dementia drugs. Regarding different stages of cognitive impairment, $24.0 \%$ $(n=25)$ of participants with mild, $46.9 \%(n=23)$ of participants with moderate and $57.1 \%(n=4)$ of participants with severe cognitive impairment received anti-dementia drugs. The average medication cost of PWD who receive an anti-dementia drug was $€ 164.12$ (SD 93.1) with a proportion of $58.7 \%$ attributable to the anti-dementia drugs. By contrast, the medication cost of PWD who did not receive anti-dementia drugs was $€ 91.47$ (SD 92.7). In the total sample, anti-dementia drugs represented $4.8 \%$ of the total number of drugs but $24.7 \%$ of the total costs. Medication cost and its share of cost for anti-dementia drugs in relation to stages of cognitive impairment are demonstrated in Fig. 1.

Possible cost reductions due to prescription of generic anti-dementia drugs were observed for the substances memantine $(-54 \%$; $€ 174.19$ versus $€ 375.00$ for package size N3), galantamine $(-56 \%$; $€ 165.00$ versus $€ 380.00$ for package size N3), donepezil ( $-91 \%$; $€ 37.52$ versus $€ 409.00$ for package size N3), and rivastigmine $(-29 \%$; $€ 85.98$ versus $€ 121.63$ for package size N1). On the basis of a consequent replacement of all 44 original anti-dementia drugs by generics, monthly average medication cost would decrease from $€ 164.12$ (SD 93.1) to $€ 118.69$ (SD 87.5). This would mean a reduction of the total medication by $27.7 \%$. Regarding the different stages of cognitive impair-

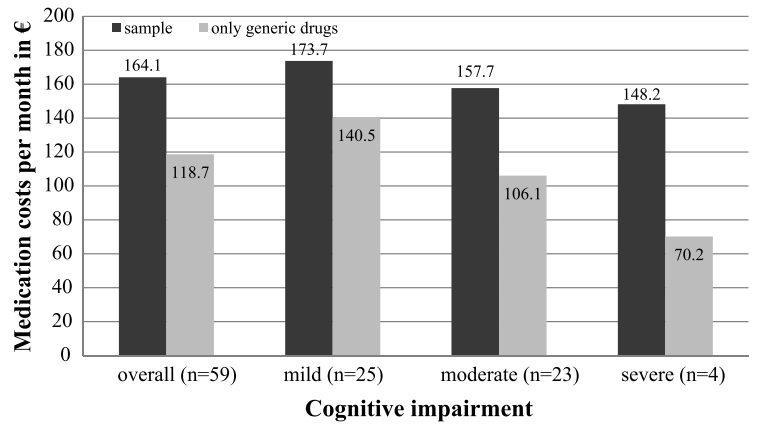

Fig. 2. Medication cost per month of persons with dementia $(n=59)$ who received a medical treatment with anti-dementia drugs and estimated medication cost that would result from consequent replacing the original anti-dementia drugs with generic alternatives.

ment in our sample, monthly cost would decrease to $€ 140.45$ (SD $88.5 ;-19 \%$ ) in mildly, to $€ 106.12$ (SD $87.5 ;-33 \%$ ) in moderately and to $€ 70.23$ (SD 87.56; $-53 \%$ ) in severely cognitively impaired PWD. Figure 2 demonstrates real and estimated medication cost of PWD who received anti-dementia drugs.

\section{Associations between medication cost, cost per \\ drug and number of drugs taken and socio-demographic and clinical variables}

Table 3 shows the results of the mixed regression models, which analyzed the associations between medication cost, cost per drug, and the number of drugs taken and socio-demographic and clinical variables. Total medication cost of PWD was positively associated with deficits in ADL $(b=9.56 ; p=0.006)$

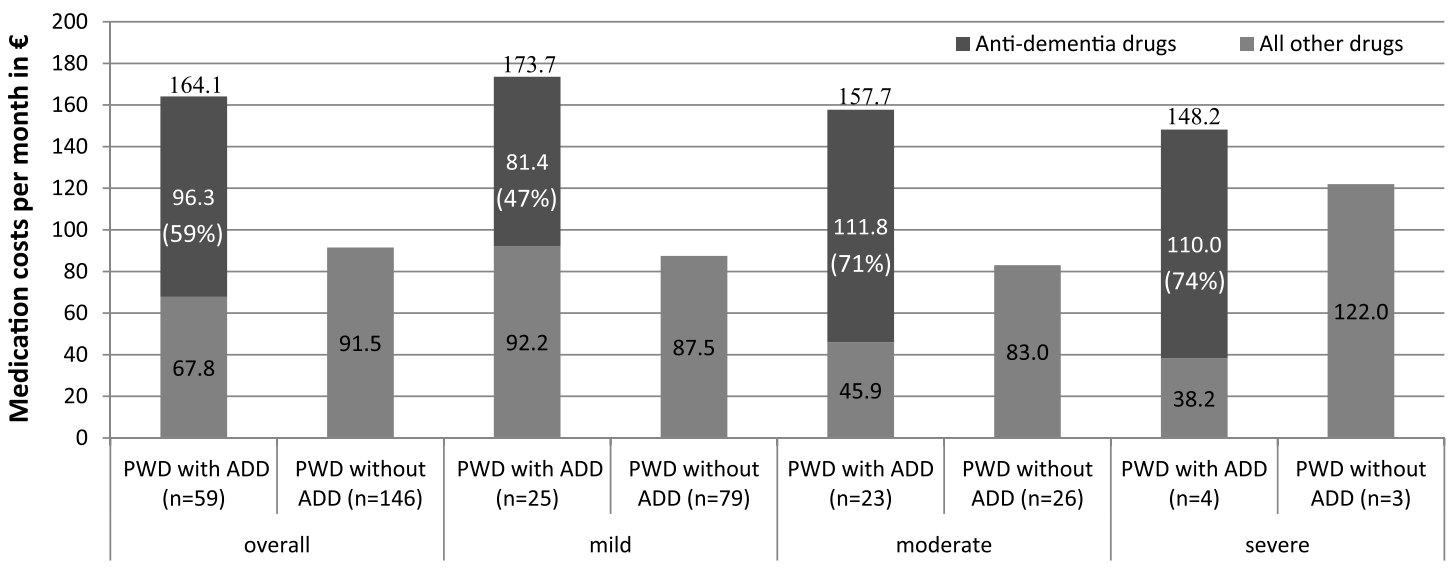

Cognitive impairment and drug treatment

Fig. 1. Medication costs per month and cost for anti-dementia drugs (percentage in parentheses) for participants with $(n=59)$ and without $(n=146)$ anti-dementia drug treatment. PWD, persons with dementia; ADD, anti-dementia drug treatment. 
Table 3

Multivariable associations between medication costs, costs per drug and number of taken drugs and socio-demographic and clinical variables

\begin{tabular}{|c|c|c|c|c|c|c|c|c|c|}
\hline & \multicolumn{3}{|c|}{ Cost per month ${ }^{1}$} & \multicolumn{3}{|c|}{ Cost per drug ${ }^{1}$} & \multicolumn{3}{|c|}{ Number of drugs taken ${ }^{2}$} \\
\hline & $\mathrm{b}$ & $(\mathrm{SE})$ & $p$ value & $\mathrm{b}$ & $(\mathrm{SE})$ & $p$ value & $\mathrm{b}$ & $(\mathrm{SE})$ & $p$ value \\
\hline Gender (Ref.female) & -4.87 & $(10.39)$ & 0.639 & -4.25 & $(2.89)$ & 0.141 & 0.033 & $(0.07)$ & 0.656 \\
\hline Age & -3.34 & (1.34) & 0.013 & -0.42 & $(0.27)$ & 0.116 & 0.001 & $(0.01)$ & 0.906 \\
\hline Living Situation (Ref. living alone) & -2.07 & (11.79) & 0.860 & -2.06 & $(3.11)$ & 0.508 & 0.052 & $(0.07)$ & 0.457 \\
\hline Number of ICD-10 diagnosis & 3.06 & $(1.54)$ & 0.047 & -0.44 & $(0.27)$ & 0.103 & 0.038 & $(0.01)$ & 0.001 \\
\hline Severity of dementia (MMST-value $)^{3}$ & 1.09 & $(1.44)$ & 0.446 & -0.67 & $(0.34)$ & 0.047 & 0.024 & $(0.01)$ & 0.001 \\
\hline Activities of daily living $(B-A D L)$ & 9.56 & $(3.48)$ & 0.006 & 1.91 & $(0.97)$ & 0.049 & 0.001 & $(0.02)$ & 0.916 \\
\hline Depression $(G D S)$ & -8.90 & $(43.33)$ & 0.837 & -6.68 & $(8.71)$ & 0.443 & 0.062 & $(0.19)$ & 0.743 \\
\hline In-hospital stays ${ }^{4}$ & 6.54 & $(16.24)$ & 0.687 & -3.92 & $(2.52)$ & 0.120 & 0.125 & $(0.08)$ & 0.100 \\
\hline Intercept & 303.57 & $(115.56)$ & 0.009 & 76.15 & $(23.46)$ & 0.001 & 0.711 & $(0.51)$ & 0.164 \\
\hline $\mathrm{R}^{2}$ within & 0.120 & & - & 0.161 & & - & - & & - \\
\hline $\mathrm{R}^{2}$ between & 0.084 & & - & 0.128 & & - & - & & - \\
\hline $\mathrm{R}^{2}$ overall & 0.094 & & 0.001 & 0.149 & & 0.001 & - & & 0.001 \\
\hline $\mathrm{n}$ & 205 & & - & 203 & & - & 205 & & - \\
\hline
\end{tabular}

${ }^{1}$ Linear mixed model with random effects for general practitioner; standard errors were estimated with a nonparametric bootstrapping (2,000 replications); ${ }^{2}$ Poisson regression model with random effects for general practitioner; standard errors were estimated by observed information matrix; ${ }^{3}$ MMST-value reverse-coded; ${ }^{4}$ In-hospital stays - days in the 12 months prior to baseline assessment. b, observed coefficient; SE, standard error; ICD, International Statistical Classification of Diseases and Related Health Problems; MMST, Mini-Mental Status-Test; B-ADL, Bayer-Activities of Daily Living Scale; GDS, Geriatric Depression Scale.

and number of ICD-10 diagnoses $(b=3.06 ; p=0.047)$. Furthermore, there was a negative association between medication cost and participants' age $(b=-3.34$; $p=0.013)$. In this linear mixed regression model, the association between medication cost with cognitive impairment was no longer statistically significant $(p=0.446)$. With regard to cost per drug, we found a negative association with severity of cognitive impairment $(b=-6.70 ; p=0.047)$ and a positive association with ADL $(b=1.91 ; p=0.049)$. Number of drugs taken was also positively associated with both the number of ICD-10 diagnoses $(b=0.04 ; p=0.001)$ and the severity of cognitive impairment $(b=0.02 ; p=0.001)$. Finally, medication cost, cost per drug and number of drugs taken were not associated with any of the clinical variables, including depression and in-hospital stays, nor with socio-demographic variables, such as gender and living situation.

\section{DISCUSSION}

Total medication cost is higher in PWD with moderate $(€ 118.09)$ and severe $(€ 136.93)$ compared to mild cognitive impairment (€108.19). Our results are consistent with previously published COI studies $[18,20$, 30]. Schwarzkopf et al. [18] estimated, on the basis of secondary data, a monthly medication cost of $€ 127$ in PWD with mild and $€ 149$ with moderate dementia. Leicht et al. [20] measured a medication cost of $€ 116$ in PWD with mild and $€ 148$ in PWD with moderate dementia on the basis of a questionnaire. Minor differences in costs could be attributed to the different age of the study populations, the respective methods of cost calculation and allocation of people to the categories of dementia severity. Our results are not consistent with previous reports of considerably lower medication cost in severe dementia $[19,20,29,30]$, which could be due to the high proportion $(51.7 \%)$ of our patients who received high-priced anti-dementia drugs and the high average number of ICD-10 diagnoses of our severely impaired patients.

Medication cost is associated with activities of daily living, comorbidity, and age. Our results suggest an increase of medication cost with progression of impairment in activities of daily living and an increasing number of diagnoses. These results are consistent with results of previously published studies. Across these studies, functional impairment was in particular associated with higher cost of care, especially with medical cost in dementia [31-34]. Zhu et al. [33] found a significant association between comorbidity and medical cost in dementia, but it must be kept in mind that medication cost is only a small proportion of total medical cost. In addition, we found a negative association with age, which indicates decreasing medication cost with increasing age of PWD. It would be reasonable to expect that number of diagnoses, number of prescribed drugs and consequently medication cost will increase with age. However, in our sample no correlation between age and cognitive impairment or age and number of diagnoses was observed. This could be attributable to the small number of participants above age 70. Another reason could be our specific sample of PWD, who were living at home 
predominantly in sparsely populated rural regions in Mecklenburg-Western Pomerania. This could lead to reduced mobility and restricted access to out-patient medical care, particularly for PWD in old age [41]. Furthermore, age-related changes of pharmacokinetics and pharmacodynamics could result in a less favorable benefit-risk assessment for medication of the general practitioner [48, 49] and, consequently, in lower medication cost in old age.

Within the domain of medication cost, anti-dementia drugs were the crucial cost drivers. A prescription for an anti-dementia drug almost doubles medication cost of PWD ( $€ 164.12$ versus $€ 91.47$ ), meaning anti-dementia drugs made up 59\% of our PWD's medication cost. These findings are consistent with results of Kiencke et al. [14], who determined medication cost of $€ 147.17$, with a share of $58 \%$ for memantine in a sample of anonymized data of patients with Alzheimer's disease who were insured by a large German statutory health insurance company. Thus, prescription of generic anti-dementia drugs could result in a less costly drug treatment of PWD, particularly in PWD with moderate and severe cognitive impairment. This estimation is based on the current price reduction of generic versions versus the original anti-dementia drugs, such as memantine $(-54 \%)$, galantamine $(-56 \%)$, donepezil $(-91 \%)$, and rivastigmine $(-29 \%)$. On the one hand, these theoretical savings are overestimated because prescription choices of anti-dementia drugs will not be solely based on the most economically advantageous tender. Instead, it should rather be expected that in the future, drug prescription will be a mixture of both cost-intensive original and economically more favorable generic anti-dementia drugs. Demonstrated real and estimated medication costs could be interpreted as a plausible range of medication costs of community-dwelling PWD in future. On the other hand, it is possible that prescription of anti-dementia drugs will increase due to currently available generics. Therefore, our analysis does not allow for a reliable prediction of medication cost of PWD who do not currently receive anti-dementia drugs. Furthermore, positive effects of medication treatment with anti-dementia drugs, such as preservation of cognitive abilities [10], reduced need for care [11, 12] or a delay of institutionalization [13], could occur more often. These effects could reduce formal and informal health care cost of PWD. From a health-economic perspective, the replacement of original substances with generic anti-dementia drugs should be supported. The development of total medication costs for PWD should be monitored.
People with higher levels of cognitive impairment received a drug regimen with fewer but more expensive drugs. Descriptive statistics showed that people with severe cognitive impairment received on average only 2.71 (SD 1.89) drugs with an average cost per drug of $€ 60.04$ (SD 54.18). In contrast, people with mild cognitive impairment received on average 6.28 (SD 3.43) drugs with a cost per drug of approximately $€ 18.42$ (SD 15.47). Therefore, in our analysis, increasing cognitive impairment was associated with higher cost per drug and fewer drugs taken. Effects of cognitive impairment on total formal or informal health care costs could not be determined validly in previous studies [31-34]. However, the progression of dementia disease is accompanied by gradual deterioration in specific cognitive functions, such as ability to speak (aphasia), motoric capabilities (apraxia), and awareness (agnosia), and a higher prescription rate of anti-dementia drugs [9]. This could be the reason for a drug treatment with only the most essential and the most expensive drugs in moderate and, particularly, in severe cognitive impairment. Nevertheless, a less comprehensive pharmacotherapy might be inadequate for multimorbid PWD with moderate and severe cognitive impairment. The average number of ICD-10 diagnoses (mean $=9.24)$ underlines the considerable multimorbidity of PWD in our sample. The significant negative association of cognitive impairment with number of drugs taken and cost per drug could implicate an inadequate drug treatment of multimorbid PWD. This should be investigated in further studies.

\section{ACKNOWLEDGMENTS}

This study is part of the DelpHi-MV trial (Dementia: Life- and person-centered help in MecklenburgWestern Pomerania) and was fund by the German Center for Neurodegenerative Diseases (DZNE) and the University Medicine of Greifswald.

Authors' disclosures available online (http://www.jalz.com/disclosures/view.php?id=2305).

\section{SUPPLEMENTARY MATERIAL}

The supplementary table is available in the electronic version of this article: http://dx.doi.org/10.3233/ JAD-140804.

\section{REFERENCES}

[1] World Health Organization (2012) Dementia: A public health priority. 
[2] Fendrich K, Hoffmann W (2007) More than just aging societies: The demographic change has an impact on actual numbers of patients. J Public Health 15, 345-351.

[3] Hampel H, Prvulovic D, Teipel S, Jessen F, Luckhaus C, Frolich L, Riepe MW, Dodel R, Leyhe T, Bertram L, Hoffmann W, Faltraco F (2011) The future of Alzheimer's disease: The next 10 years. Prog Neurobiol 95, 718-728.

[4] Lux G, Steinbach P, Wasem J, Weegen L, Walendzik A (2013) Demografie und Morbiditätsentwicklung. In KrankenhausReport 2013: Mengendynamik: Mehr Menge, mehr Nutzen? Klauber J, Geraedts M, Friedrich J, Wasem J, eds. Schattauer $\mathrm{GmbH}$, Stuttgart, pp. 69-82.

[5] Statistisches Bundesamt, Gesundheit (2010) Krankheitskosten 2002, 2004, 2006 und 2008. 12, 1-45.

[6] Statistische Ämter des Bundes und der, Länder (2007) Demografischer Wandel in Deutschland - Bevölkerungs- und Haushaltsentwicklung im Bund und in den Ländern. 2, 2-37.

[7] Wimo A, Jonsson L, Winblad B (2006) An estimate of the worldwide prevalence and direct costs of dementia in 2003. Dement Geriatr Cogn Disord 21, 175-181.

[8] Prince M, Bryce R, Albanese E, Wimo A, Ribeiro W, Ferri CP (2013) The global prevalence of dementia: A systematic review and metaanalysis. Alzheimers Dement 9, 63-75.

[9] Deutsche Gesellschaft für Psychiatrie PuND, Deutsche Gesellschaft für, Neurologie (2009) (DGN), S-3 Leitlinie "Demenzen", http://www.dgppn.de/fileadmin/user_upload/_ medien/download/pdf/kurzversion-leitlinien/s3-leitlinie-dem enz-lf.pdf, Last updated February 17, 2010, Accessed on March 4, 2014, pp.

[10] Köber R (2012) Therapeutisches Drug Monitoring von Antidementiva - Implementierung eines neuen HPLC/UVAnsatzes für das TDM aller Antidementiva in der medizinischen Routineanalytik und seine Relevanz für die Pharmakotherapie im gerontopsychiatrischen Klinikalltag, Verlag Dr, Kovac, Hamburg, pp.

[11] Wimo A, Winblad B, Stoffler A, Wirth Y, Mobius HJ (2003) Resource utilisation and cost analysis of memantine in patients with moderate to severe Alzheimer's disease. Pharmacoeconomics 21, 327-340.

[12] Reisberg B, Doody R, Stoffler A, Schmitt F, Ferris S, Mobius HJ (2003) Memantine in moderate-to-severe Alzheimer's disease. $N$ Engl J Med 348, 1333-1341.

[13] Sano M, Wilcock GK, van BB, Kavanagh S (2003) The effects of galantamine treatment on caregiver time in Alzheimer's disease. Int J Geriatr Psychiatry 18, 942-950.

[14] Kiencke P, Rychlik R, Grimm C, Daniel D (2010) [Cost of illness in Alzheimer's disease]. Med Klin (Munich) 105, 327333.

[15] Migliaccio-Walle K, Getsios D, Caro JJ, Ishak KJ, O’Brien JA, Papadopoulos G (2003) Economic evaluation of galantamine in the treatment of mild to moderate Alzheimer's disease in the United States. Clin Ther 25, 1806-1825.

[16] Fillit HM (2000) The pharmacoeconomics of Alzheimer's disease. Am J Manag Care 6, 1139-1144.

[17] Feldman H, Gauthier S, Hecker J, Vellas B, Hux M, Xu Y, Schwam EM, Shah S, Mastey V (2004) Economic evaluation of donepezil in moderate to severe Alzheimer disease. Neurology 63, 644-650.

[18] Schwarzkopf L, Menn P, Kunz S, Holle R, Lauterberg J, Marx P, Mehlig H, Wunder S, Leidl R, Donath C, Graessel E (2011) Costs of care for dementia patients in community setting: An analysis for mild and moderate disease stage. Value Health 14, 827-835.

[19] Hallauer J, Schons M, Smala A, Berger K (2000) Untersuchung von Krankheitskosten bei Patienten mit
Alzheimer-Erkrankung in Deutschland. Gesundh ökon Qual manag 5, 73-79.

[20] Leicht H, Heinrich S, Heider D, Bachmann C, Bickel H, van den BH, Fuchs A, Luppa M, Maier W, Mosch E, Pentzek M, Rieder-Heller SG, Tebarth F, Werle J, Weyerer S, Wiese B, Zimmermann T, Konig HH (2011) Net costs of dementia by disease stage. Acta Psychiatr Scand 124, 384-395.

[21] Quentin W, Riedel-Heller SG, Luppa M, Rudolph A, Konig HH (2010) Cost-of-illness studies of dementia: A systematic review focusing on stage dependency of costs. Acta Psychiatr Scand 121, 243-259.

[22] Ernst RL, Hay JW, Fenn C, Tinklenberg J, Yesavage JA (1997) Cognitive function and the costs of Alzheimer disease. An exploratory study. Arch Neurol 54, 687-693.

[23] Hauber AB, Gnanasakthy A, Snyder EH, Bala MV, Richter A, Mauskopf JA (2000) Potential savings in the cost of caring for Alzheimer's disease. Treatment with rivastigmine. Pharmacoeconomics 17, 351-360.

[24] Jonsson L (2004) Economic evidence in dementia: A review. Eur J Health Econ 5(Suppl 1), 30-35.

[25] Wimo A, Ljunggren G, Winblad B (1997) Costs of dementia and dementia care: A review. Int J Geriatr Psychiatry 12, 841-856.

[26] Leung GM, Yeung RY, Chi I, Chu LW (2003) The economics of Alzheimer disease. Dement Geriatr Cogn Disord 15, 34-43.

[27] Schwarzkopf L, Menn P, Leidl R, Wunder S, Mehlig H, Marx P, Graessel E, Holle R (2012) Excess costs of dementia disorders and the role of age and gender - an analysis of German health and long-term care insurance claims data. BMC Health Serv Res 12, 165.

[28] Leitliniengruppe Hessen (2013) Hausärztliche Leitline-Multimedikation, http://www.pmvforschungsgruppe.de/pdf/03 publikationen/multimedikation_ll.pdf, 1-104, Last updated February 4, 2012, Accessed on March 4, 2014.

[29] Lopez-Bastida J, Serrano-Aguilar P, Perestelo-Perez L, OlivaMoreno J (2006) Social-economic costs and quality of life of Alzheimer disease in the Canary Islands, Spain. Neurology 67, 2186-2191.

[30] Jonsson L, Eriksdotter JM, Kilander L, Soininen H, Hallikainen M, Waldemar G, Nygaard H, Andreasen N, Winblad B, Wimo A (2006) Determinants of costs of care for patients with Alzheimer's disease. Int J Geriatr Psychiatry 21, 449459.

[31] Leicht H, Konig HH, Stuhldreher N, Bachmann C, Bickel H, Fuchs A, Heser K, Jessen F, Kohler M, Luppa M, Mosch E, Pentzek M, Riedel-Heller S, Scherer M, Werle J, Weyerer S, Wiese B, Maier W (2013) Predictors of costs in dementia in a longitudinal perspective. PLOS ONE 8, e70018.

[32] Zhu CW, Leibman C, McLaughlin T, Zbrozek AS, Scarmeas N, Albert M, Brandt J, Blacker D, Sano M, Stern Y (2008) Patient dependence and longitudinal changes in costs of care in Alzheimer's disease. Dement Geriatr Cogn Disord 26, 416423.

[33] Zhu CW, Scarmeas N, Torgan R, Albert M, Brandt J, Blacker D, Sano M, Stern Y (2006) Clinical characteristics and longitudinal changes of informal cost of Alzheimer's disease in the community. J Am Geriatr Soc 54, 1596-1602.

[34] Andersen CK, Lauridsen J, Andersen K, Kragh-Sorensen P (2003) Cost of dementia: Impact of disease progression estimated in longitudinal data. Scand J Public Health 31, 119-125.

[35] Calabrese P, Kessler J (2000) Screening for cognitive impairment in dementia - the DemTect procedure. Eur Neuropsychopharmacol 10, 369. 
[36] Thyrian JR, Fiss T, Dreier A, Bowing G, Angelow A, Lueke S, Teipel S, Flessa S, Grabe HJ, Freyberger HJ, Hoffmann W (2012) Life- and person-centred help in MecklenburgWestern Pomerania, Germany (DelpHi): Study protocol for a randomised controlled trial. Trials $\mathbf{1 3}, 56$.

[37] Eichler T, Thyrian JR, Dreier A, Wucherer D, Kohler L, Fiss T, Bowing G, Michalowsky B, Hoffmann W (2014) Dementia care management: Going new ways in ambulant dementia care within a GP-based randomized controlled intervention trial. Int Psychogeriatr 26, 247-256.

[38] Dreier A, Thyrian JR, Hoffmann W (2011) Dementia Care Manager in der ambulanten Demenzversorgung: Entwicklung einer innovativen Qualifizierung für Pflegefachkräfte. Pflege\& Gesellschaft 16, 53-64.

[39] Fiss T, Thyrian JR, Wucherer D, Assmann G, Kilimann I, Teipel SJ, Hoffmann W (2013) Medication management for people with dementia in primary care: Description of implementation in the DelpHi study. BMC Geriatr 13, 121.

[40] Meyer J, Ostrzinski S, Fredrich D, Havemann C, Krafczyk J, Hoffmann W (2012) Efficient data management in a large-scale epidemiology research project. Comput Methods Programs Biomed 107, 425-435.

[41] WIdO. (Wissenschaftliches Institut der AOK) (2013) GKV-Arzneimittelindex, http://www.wido.de/gkv-arzneimit telind.html.
[42] Deutsches Institut für medizinische Dokumentation und Information (DIMDI) (2012) Klassifikation, Terminologien und Standards im Gesundheitswesen, http://www.dimdi.de/ static/de/klassi/index.htm

[43] Kessler J, Markowitsch HJ, Denzler P (1990) Mini-MentalStatus-Test (MMST) [German Version].

[44] Hindmarch I, Lehfeld H, de JP, Erzigkeit H (1998) The Bayer Activities of Daily Living Scale (B-ADL). Dement Geriatr Cogn Disord 9(Suppl 2), 20-26.

[45] Gauggel S, Birkner B (1999) Validity and reliability of a German version of the Geriatric Depression Scale (GDS). Zeitschrift für klinische psychologie - Forschung und Praxis 28, 18-27.

[46] Desgagne A, Castilloux AM, Angers JF, LeLorier J (1998) The use of the bootstrap statistical method for the pharmacoeconomic cost analysis of skewed data. Pharmacoeconomics 13, 487-497.

[47] StataCorp (2009) Stata Statistical Software: Release 11.

[48] Schumbach K (2012) Memantin jetzt auch generisch, http://www.apotheke-adhoc.de/nachrichten/nachrichtdetail/memantin-jetzt-auch-generisch/, Last updated October 9, 2012, Accessed on March 4, 2014.

[49] Wehling M, Burkhardt H (2010) Arzneitherapie für Ältere, Springer, Berlin. 